\title{
Tryptophan in Membrane-active Synthetic Antimicrobials
}

\author{
Joseph W. Meisel ${ }^{1}$, Mohit B. Patel ${ }^{2}$, Saeedeh Negin ${ }^{1}$, Michael R. Gokel ${ }^{1}$, \\ Ryan Cantwell ${ }^{1}$ and George W. Gokel ${ }^{1,2^{*}}$
}

${ }^{1}$ Department of Chemistry and Biochemistry, Center for Nanoscience, University of Missouri-St. Louis, 1 University Blvd., St. Louis, MO 63121, USA; '2Department of Biology, Center for Nanoscience, University of Missouri-St. Louis, 1 University Blvd., St. Louis, MO 63121, USA

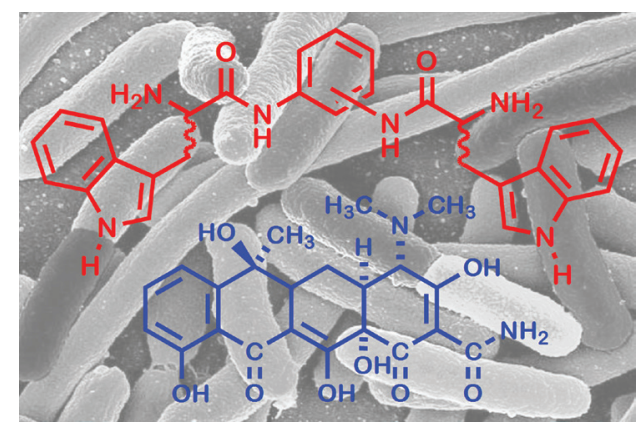

\begin{abstract}
Herein, we summarize the background data that has led to a new class of antimicrobial amphiphiles and present recent results showing reversal of resistance to antibiotics in an Escherichia coli strain incorporating a tetracycline-selective efflux pump. In addition, two types of amphiphiles that show antibiotic potency enhancement or resistance reversal are discussed, along with our knowledge on the evolution that led to the active structures. One family is based on macrocyclic crown polyethers, which are known to insert into both liposomal and bacterial bilayers; these compounds are termed as hydraphiles and consist of three diazacrown rings linked by alkyl spacers and terminated by benzyl groups. In contrast, the second type of amphiphiles use tryptophans as the terminal, membrane anchoring residues; in this group of amphiphiles, two tryptophans are connected by alkyl chains or aryl groups. In both cases, however, the antibacterial activity of certain members of each family was apparent. Further, the amphiphiles have been shown to act as adjuvants that increase the potency of such antimicrobials as tetracycline and even to have re-sensitized a tetracycline-resistant $E$. coli strain to the antibiotic.
\end{abstract}

Introduction

Among the 20 genetically-encoded amino acids, the occurrence of

Keywords: Amphiphile; Antibiotic; Antibiotic Resistance; Bis(tryptophan); Cationpi; Escherichia coli; Hydraphile; Indole; Re-sensitization; Resistant bacteria; Synthetic anion transporter; Tryptophan.

Abbreviations: $\mathrm{Tet}^{\mathrm{R}}$, tetracycline-resistant E. coli; THF, tetrahydrofuran; ${ }^{23} \mathrm{Na}-\mathrm{NMR}$, sodium-nuclear magnetic resonance spectroscopy; FDA, fluorescein diacetate.

Received: September 28, 2016; Revised: January 04, 2017; Accepted: January 05, 2017

"Correspondence to: George W. Gokel, Department of Chemistry \& Biochemistry, Center for Nanoscience, University of Missouri-St. Louis, St. Louis, MO 63121, USA. Tel: 314/516-5321, Fax: 314/516-5342, E-mail: gokelg@umsl.edu

How to cite this article: Meisel JW, Patel MB, Negin S, Gokel MR, Cantwell R, Gokel GW. Tryptophan in Membrane-active Synthetic Antimicrobials. J Explor Res Pharmacol 2017;2(1):7-15. doi: 10.14218/JERP.2016.00025 tryptophan (Trp, W) in proteins is the least common..$^{1}$ It is present at a frequency of about $1.3 \%$ in all known proteins. This compares with $3.9 \%$ for phenylalanine and $3.3 \%$ for tyrosine, the other electron-rich aromatic amino acids. Tryptophan typically occurs in peptides and proteins at the membrane interfaces, suggesting an amphiphilic role. ${ }^{2}$ Examples are the bacterial peptide that forms ion channels, gramicidin, and the voltage-gated protein $\mathrm{KcsA} \mathrm{K}$ channel..$^{3-6}$ The structures of tryptophan and indole are shown in Scheme 1.

Gramicidin forms a channel by dimerizing and exposing its Leu-Trp repeats to the polar (external) surfaces of membranes. The dimeric nature and the organization within the bilayer have been extensively studied, ${ }^{7}$ albeit not without the results representing some controversy. ${ }^{7-9}$ A synthetic channel in which two gramicidin peptides were linked by a tartaric acid residue showed function similar to the individual peptides. ${ }^{10}$ Other semi-synthetic 

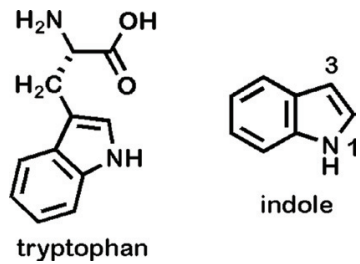

Scheme 1. The chemical structures of tryptophan and indole. The 1- and 3- positions of indole are numbered.

gramicidin mimics have been prepared as well. ${ }^{11,12}$ Figure 1 shows schematic illustrations of gramicidin (variant $\mathrm{C}$ ), the $\mathrm{KcsA} \mathrm{K}^{+}$conducting channel and the $\mathrm{ClC} \mathrm{Cl}^{-}$-conducting channel. ${ }^{13}$

Our initial interest in tryptophan's indole was piqued by at least three factors. The first was its ubiquity at membrane boundaries, as noted above. The second was the observation of a high proportion of tryptophan in the periplasmic loops of the photosynthetic reaction center. ${ }^{16}$ These loops connect the transmembrane segments, and a "needle and thread" mechanism was proposed, whereby tryptophans in periplasmic loops guide protein segments through bilayers during the process of translocation; furthermore, tryptophan is suggested to serve as an eventual protein anchor in these situations. ${ }^{17}$

The third stimulus of our interest was related to an interesting indole compound reported by Schore and Turro. ${ }^{18}$ Those researchers prepared an indole derivative, which they referred to as "6-In11 " and in which the 3 -carbon of indole was substituted by an $n$ hexyl group and the nitrogen was substituted by $-\left(\mathrm{CH}_{2}\right)_{11} \mathrm{~N}^{+}\left(\mathrm{CH}_{3}\right)_{3}$ $\mathrm{Br}^{-}$. The compounds disclosed in the publication were designed as fluorescent probes of micellar systems; however, the compound 6-In-11 did not show the expected amphiphilic behavior. We speculated that both indole and the quaternary ammonium residue were competing as head groups, altering the anticipated extended conformation of the indole-containing chain.

Taken together, the remarkable properties of tryptophan and its aromatic residue, indole, led us to explore its potential as an amphiphile head group, as a pi-donor for alkali metal cations, and as a membrane-active synergist for antimicrobials against resistant bacteria. The results of those studies are recounted below.

Indole as an amphiphilic head group.

The formation of liposomes by twin-tailed amphiphiles is common. ${ }^{19}$ Single-chained amphiphiles typically form micelles, although vesicle formation has long been known. ${ }^{20}$ Our initial studies sought to determine if the indole residue was sufficiently polar to serve as a head group. The second question we investigated was whether an alkylindole having a sufficiently long chain would form micelles or liposomes. In either case, a third question was how, if at all, the formation of aggregates was altered by alkylation on nitrogen (1-position) or at the 3-position. Indole is linked at the 3-position in tryptophan.

Indole can be deprotonated at nitrogen to form an ambident anion. ${ }^{21}$ We found that treatment with $\mathrm{NaH}$ in THF followed by reaction with an alkyl halide afforded the $N$-alkylated indoles in yields of about $60 \% .^{22}$ The by-product was likely the 3 -isomer, but this was not isolated. A similarly conducted reaction using $\mathrm{LiH}$ instead of $\mathrm{NaH}$ gave the corresponding 3 -alkyl derivatives. The latter reaction conditions produced the 3 -alkylindoles in only $20-40 \%$ yields after separation of the isomeric $N$-alkylated product. ${ }^{23,24}$

Aggregate formation was attempted by using either the reversed-phase or the lipid hydration method. ${ }^{25,26}$ The methyl or $n$ hexyl substituted indoles designated 1, 2, 6, and 7 failed to form any aggregate that could be detected either by light scattering or transmission electron microscopy (TEM). The other compounds did form aggregates, which fell within the size range of $1500 \AA$ to $4000 \AA(150-400 \mathrm{~nm})$. Where possible, electron micrographs were obtained, and the sizes determined by the two methods were in reasonable agreement. The formation of vesicles from these singletail amphiphiles was confirmed by TEM and by freeze-fracture and dye entrapment methods. ${ }^{24}$

A surprising finding of this study concerned aggregate stability. We anticipated that amphisomes which formed from 3-alkylindoles would be more stable than the isomeric $\mathrm{N}$-alkylindoles. This was because the indole in tryptophan itself is substituted in the 3-position and has a free $>\mathrm{N}-\mathrm{H}$. Although similar isomer stabilities were observed in some cases, the 3- $n$-decylindole (8) aggregates proved to be frail and the aggregate size increased over time for 3 - $n$-octadecylindole (9), but the aggregates formed from isomeric 4 were stable for more than a month.

Notwithstanding the surprising stability profiles, it was clear that indole itself could function effectively as an amphiphilic head group. Moreover, the evidence of formation of spherical aggregates that included a fluorescent dye confirmed the formation of vesicular, rather than micellar, assemblies.

Indole as a hydraphile head group

In a separate effort, we developed a family of cation-conducting pore-formers that we termed as 'hydraphiles' ${ }^{27}$ These molecules typically consist of three crown ether rings, connected by alkyl chains and terminated by alkyl, aryl, aralkyl or heteroaryl residues. A generalized structure is illustrated in Scheme 3.
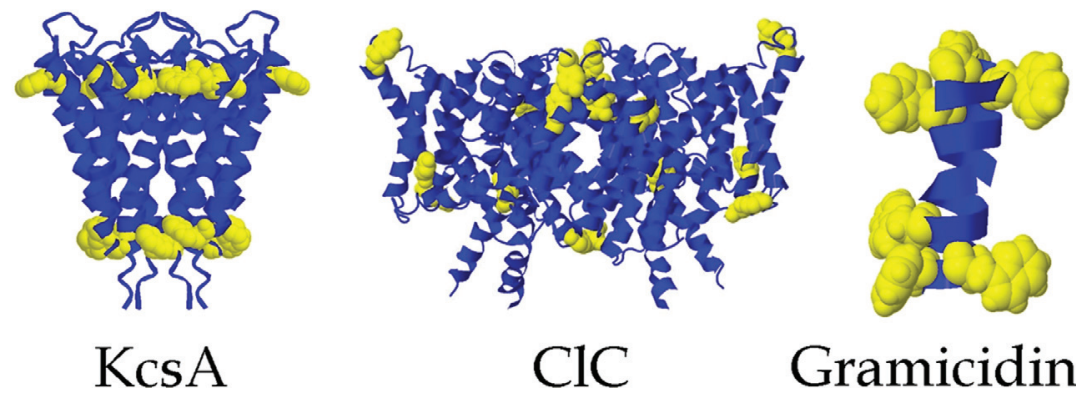

\section{Gramicidin C}

Fig. 1. Schematic representations (from solid state structures) of the KcsA $\mathrm{K}^{+}$-conducting channel (PDB: 1BL8), the $\mathrm{CIC} \mathrm{Cl}^{-}$-conducting channel (PDB: $1 \mathrm{KPK})$, and the gramicidin variant known as "C" (PDB: 1JO4). ${ }^{3,6,14,15}$ 


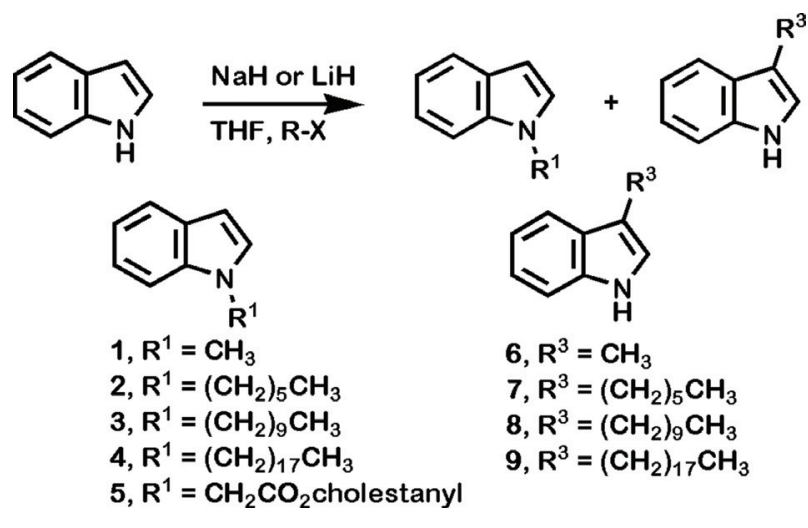

Scheme 2. Synthesis of $N(1)$ - or 3-substituted indoles by alkylation of the ambident anion.

The hydraphiles are synthetic amphiphiles that insert into liposomal bilayers and transport $\mathrm{Na}^{+}$cations by a pore or channel mechanism. Transport was confirmed by the ${ }^{23} \mathrm{Na}-\mathrm{NMR}$ method and by planar bilayer conductance studies. ${ }^{28,29}$ The channels were also shown to function in human embryonic kidney cells. ${ }^{30}$ Moreover, they conduct ions as monomers, are selective for $\mathrm{Na}^{+}$over $\mathrm{K}^{+}$ by $c a .4: 1$, and are blocked by $\mathrm{Ag}^{+} \cdot{ }^{27}$ A fluorescent channel $(\mathrm{R}=$ dansyl in Scheme 3) was shown to localize in the boundary layer of Escherichia coli. ${ }^{31}$ The hydraphiles show length-dependent transport function and toxicity to E. coli and Bacillus subtilis. ${ }^{32,33}$ Toxicity to the primary eukaryote Saccharomyces cerevisiae was also observed, but correlated less well with changes in the spacer chain length. Of course, E. coli and B. subtilis are bacteria and $S$. cerevisiae is a primary eukaryote, so the cellular structures are significantly different.

There is considerable evidence that the hydraphiles adopt an extended conformation within phospholipid bilayers. This may be inferred from two lines of evidence in particular. First, cation release from phospholipid vesicles is length-dependent. ${ }^{34}$ Thus, maximum ion release was observed when the spacer chains were dodecylene (12 methylenes), tetradecylene (14 methylenes), and hexadecylene (16 methylenes). The overall lengths of these three channels in an extended conformation correspond to the width of phospholipid bilayers. No ion transport was observed when the spacer chains were octylene ( 8 methylenes); however, when the chains were 18 or 20 methylenes, transport was observed but the rates were low. This was interpreted to mean that because of the excessive length, the overall conformation comprised a poorly organized conductance state. Second, in addition to our own experimental studies, computational studies verified the extended conformation and ion transport. ${ }^{35}$ This work suggested that the extended conformation was maintained during ion transport. Additional support for the extended conformation was gained in recently reported quantum mechanical studies. ${ }^{36,37}$

When $\mathrm{R}$ in the structure of Scheme 3 is 3-indolylmethyl, the channel fails to transport cations. ${ }^{38}$ It seems unlikely that protona- tion of the indole nitrogen is an issue, as its $\mathrm{pK}_{\mathrm{A}}$ is about 2.3. ${ }^{39}$ Further, the six aliphatic nitrogen atoms are more basic and will certainly protonate first. Evidence suggests that at least one indolyl $\mathrm{N}-\mathrm{H}$ is hydrogen-bonding across the face of a distal macrocycle, preventing ions from passing through. Two pieces of evidence support this hypothesis. First, the infrared spectrum showed an intramolecular hydrogen bond that did not change even with $10^{4}$-fold dilution. Second, replacing the proton on the indole nitrogen with a methyl group, which eliminates the possibility of $\mathrm{H}$-bond formation, rescued the transport function. ${ }^{34}$

The original hydraphile design envisioned the two distal macrocycles as both head groups and entry and exit portals for transient cations. ${ }^{40}$ The fact that indole's H-bond interactions prevented transport strongly supported this expectation. A hypothesis that tryptophan might also provide head group function engendered the synthesis of a central macrocycle having chains terminated by this amino acid. The anchoring potential of the tryptophan head groups suggested that their presence would augment pore stability, especially by protonation of the free amines.

The molecule was prepared from the macrocycle, having two side chains emanating from the nitrogen atoms. If we represent the parent macrocycle as $\mathrm{H}<\mathrm{N} 18 \mathrm{~N}>\mathrm{H}$, then the intermediate would be $\mathrm{H}_{2} \mathrm{~N}\left(\mathrm{CH}_{2}\right)_{12}<\mathrm{N} 18 \mathrm{~N}>\left(\mathrm{CH}_{2}\right)_{12} \mathrm{NH}_{2}$. Tryptophan was then coupled to each of the primary amines using standard protection-coupling methodology. However, when the product was evaluated for $\mathrm{Na}^{+}$ transport it failed to show function. It was concluded that the distal macrocycles were required for effective pore formation, notwithstanding the potential anchoring effect of tryptophan. ${ }^{41}$

\section{Indole as a pi-donor}

Alkali metal and ammonium ion cation-pi interactions were demonstrated in the 1980 s by mass spectrometry. ${ }^{42,43}$ Meot-Ner and Deakyne demonstrated ammonium-pi interactions by mass spectrometry. ${ }^{44}$ In the early 1990 s, cation-pi interactions were suggested as a means to control ion selectivity in the voltage-gated potassium channel. Computational methods were used to evaluate the donor abilities of benzene (phenylalanine), phenol (tyrosine) and the indole of tryptophan - representing the three common arenes in amino acids that possess electron-rich aromatic side chains. ${ }^{45}$ Site-directed mutagenesis experiments showed that this was not the explanation, but the potential for such interactions in supramolecular chemistry enhanced interest in the field. ${ }^{46}$

Our interest in tryptophan as a potential donor led us to use our lariat ether model system as a means to assess $\mathrm{Na}^{+}$- and $\mathrm{K}^{+}$pi interactions.$^{47}$ Unfortunately, attempts to do so in the 1980 s failed, owing to a poorly designed model system. ${ }^{48}$ A slight modification of the lariat ether, from $\mathrm{Ar}-\mathrm{CH}_{2}<\mathrm{N} 18 \mathrm{~N}>\mathrm{CH}_{2}-\mathrm{Ar}$ to $\mathrm{Ar}-\mathrm{CH}_{2} \mathrm{CH}_{2}<\mathrm{N} 18 \mathrm{~N}>\mathrm{CH}_{2} \mathrm{CH}_{2}-\mathrm{Ar}$, bore the hoped-for fruit. ${ }^{49} \mathrm{Ul}-$ timately, cation-pi complexation of $\mathrm{Na}^{+}$and $\mathrm{K}^{+}$was demonstrated for phenyl, phenol and indole. ${ }^{50,51}$ More recently, Petersen and coworkers have suggested that a cation-pi interaction involving tryptophan may play a role in interfacial stabilization. ${ }^{52}$

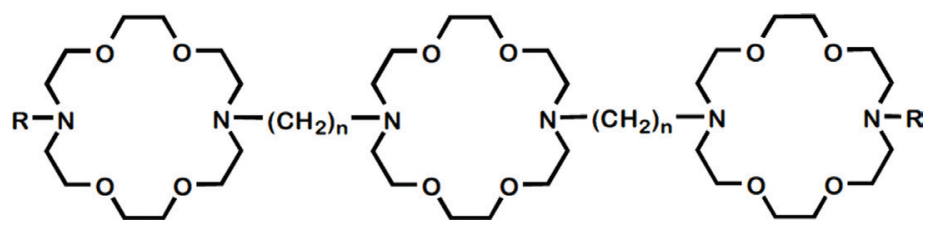

Scheme 3. Generalized structure of hydraphiles. R may be alkyl, aralkyl, aryl or heteroaryl, and $n=6-20$. 

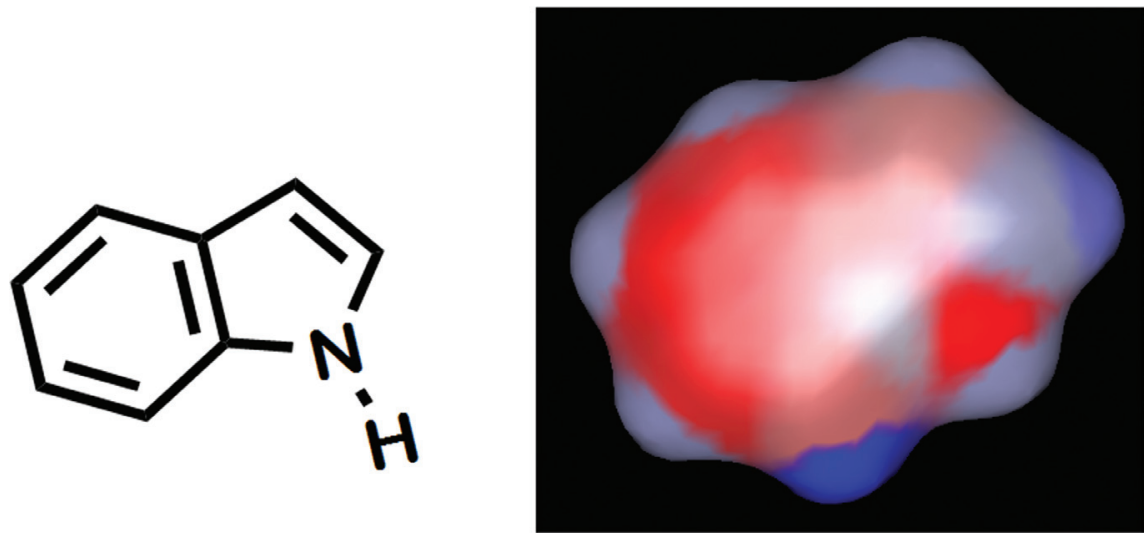

Fig. 2. Structure of indole represented in a line angle drawing and in a surface charge metaphor.

Two interesting facts emerged from these experimental studies. First, calculations of electron density were reported for benzene, phenol and indole. As expected, the donicity order was indole $>$ phenol $>$ benzene. Of the three, only indole has two rings that could potentially serve as the donor site. Calculations showed that the benzene ring of indole would be favored as a donor. This is apparent in the structures shown in Figure 2.

The panel on the right in Figure 2 shows the greatest electron density (in red) on the benzene ring, rather than the pyrrole. The prediction for cation-pi interactions is that complexation will favor an alignment of the cation with the benzene. When the structure of the lariat ether diindole complex of $\mathrm{K}^{+}$was obtained, the pyrrole end of the molecule was closest to the cation. This is apparent in the representation of the solid state structure shown in Figure 3. Two diindole- $\mathrm{K}^{+}$complexes are pictured with an iodide ion between. It is clear that both pyrrole residues in each complex are aligned with the cation. ${ }^{53}$ Solution studies conducted by NMR methods showed that the alignment was similar in acetone- $\mathrm{d}_{6}$ solution. When the lariat ether spacer chain was attached at position 5 (on the benzene ring), rather than 3 , the 6-membered ring was the primary donor.

The second interesting observation to emerge from these studies concerned the orientation and spacing of the arenes from $\mathrm{Na}^{+}$.
Using the range of solid state structures that was obtained, we were able to determine average arene-cation contact distances and angles. We compared these criteria to data from protein structures in which the water-arene contacts were inferred. Since both water and $\mathrm{Na}^{+}$have similar electron densities and scatter similarly, it is hard to distinguish them on a density map. Knowing preferred distances and angles permitted us to show that at least in some cases, a sodium cation was more likely to be in a position assigned to a water molecule. ${ }^{54}$

Influence of tryptophan in synthetic anion transporters (SATs)

The successful development of cation-transporting hydraphiles inspired our effort to develop an anion-selective synthetic poreformer. We succeeded in this by designing a family of amphiphilic peptides, the generic structure for which is shown in Figure 4.55 The key element of the design was the heptapeptide sequence. The G-X-X-P sequence in the presumed selectivity filter of the $\mathrm{ClC}$ channel fostered the selection of the $\mathrm{G}-\mathrm{G}-\mathrm{G}-\mathrm{P}$ sequence that appears in most of the compounds prepared. ${ }^{56}$ For simplicity and symmetry, the overall peptide sequence $\mathrm{G}_{3} \mathrm{PG}_{3}$ was adopted. These compounds proved generally to be active as $\mathrm{Cl}^{-}$transporters when

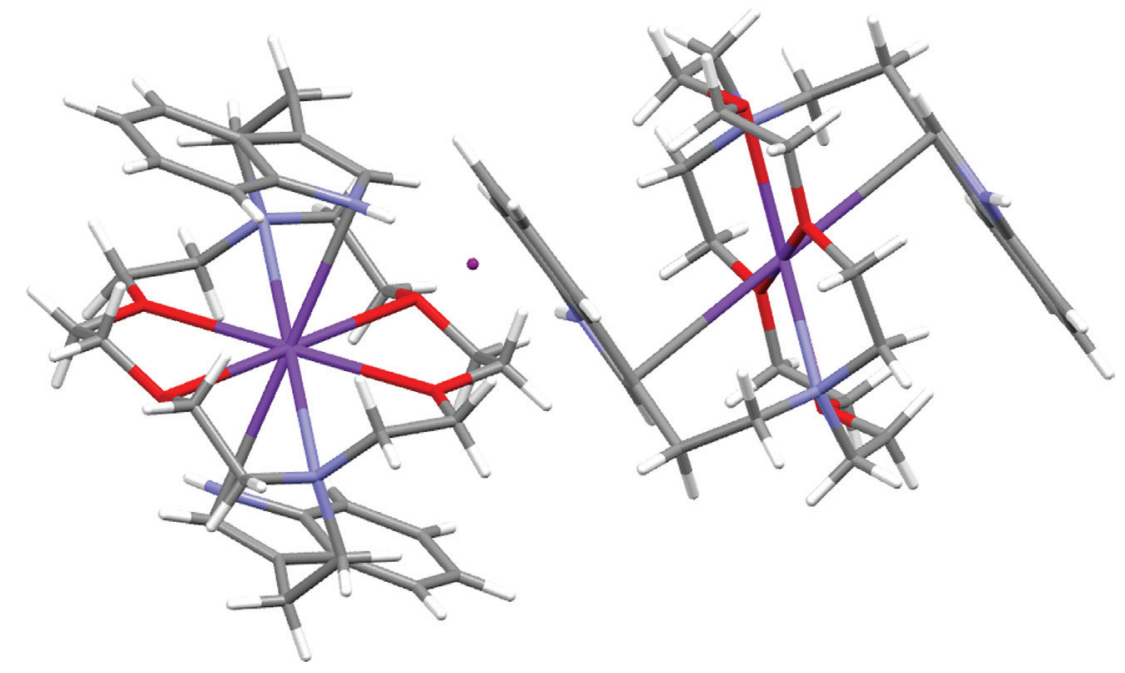

Fig. 3. Diindole lariat ether complex of $\mathrm{KI}$ showing the alignment of $\mathrm{K}^{+}$and the pyrrole ring, rather than the benzene ring, of indole. 


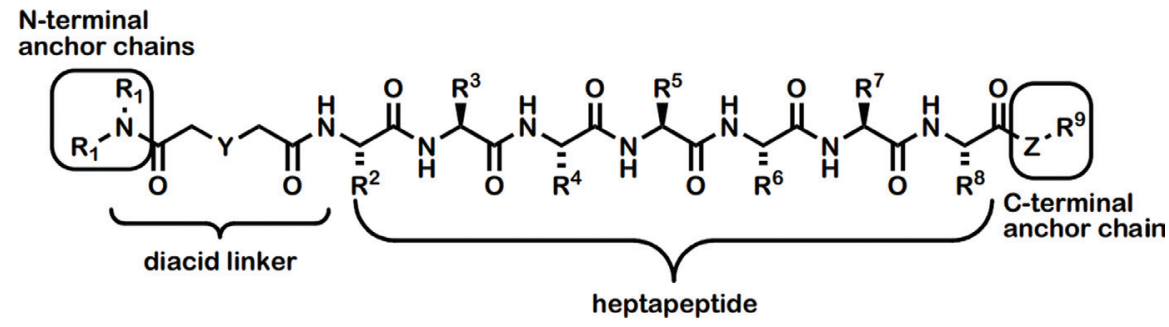

Fig. 4. Synthetic anion transporters (SATs). The four basic modules are illustrated and numerous structures were prepared that incorporate variations in each module.

the alkyl chain membrane anchors were $\geq 10$ carbons, when the diacid linker was diglycolic acid $(\mathrm{Y}=\mathrm{O})$, and when the $\mathrm{C}$-terminus $\left(\mathrm{Z}-\mathrm{R}^{9}\right)$ was benzyl or $n$-heptyl. ${ }^{57-60}$

It was found by NMR analysis that the principal H-bond donor interactions of the peptide chain occurred between $\mathrm{Cl}^{-}$and ${ }^{5} \mathrm{Gly}$ and ${ }^{7}$ Gly. ${ }^{61}$ Attention was, therefore, focused on the C-terminal side of proline. Several SATs were prepared in which positions 5, 6 and/or 7 were occupied by tryptophan residues. ${ }^{62}$ Bilayer conductance experiments showed clear and reproducible open-close behavior. ${ }^{63}$ All of the compounds successfully released $\mathrm{Cl}^{-}$from liposomes as shown in Table 1 .

The chloride ion release experiments were conducted on DOPC:DOPA ( $7: 3 \mathrm{w} / \mathrm{w})$ liposomes that were filtered to an approximate size of $2000 \AA$ (200 nm). Chloride release was monitored with a $\mathrm{Cl}^{-}$-selective electrode and the amount observed at $1800 \mathrm{~s}$ was compared to the total $\mathrm{Cl}^{-}$obtained upon vesicular lysis. The factors that influence the 6-fold difference in $\mathrm{Cl}^{-}$release were assessed in detail, but a correlation with the ability of the monomers to aggregate in aqueous solution was prominent. ${ }^{58}$

\section{Hydraphiles that increase antibiotic potency}

The fact that various hydraphiles insert into bilayers, conduct cations and alter ion homeostasis caused us to consider their potential as combination therapeutics. It was surmised that penetration of the bilayer might cause a membrane disruption that would enhance the entry of other substances. This potentially naïve notion was tested by treating the DH5 $\alpha$ strain of E. coli with sub-minimal inhibitory concentrations (MICs) of hydraphiles and the antibiotics erythromycin, kanamycin, rifampicin and tetracycline. ${ }^{64}$ The hydraphiles shown in Scheme 3 were studied, and the benzyl $\mathrm{C}_{14}$ and $\mathrm{C}_{16}$ hydraphiles proved to be most effective. The studies were conducted by first determining the MIC of the hydraphile against

Table 1. Percent chloride ion release from DOPC/DOPA (7:3) liposomes at $1800 \mathrm{~s}$

\begin{tabular}{ll}
\hline Peptide sequencea & $\% \mathrm{Cl}^{-}$released \\
\hline GGGPGGG & 35 \\
GGGPWGG & 10 \\
GGGPWGG & 21 \\
GGGPGWG & 40 \\
GGGPGGW & 25 \\
GGGPGGW(N-CHO) & 60 \\
GGGPGGW(N-CH $)$ & 30 \\
\hline
\end{tabular}

a. All isomers are I except " $w$ " which indicates D-Trp. the bacterium. ${ }^{65}$ The MIC was then determined for the antibiotic against the bacterium. In the co-administration experiment, bacteria were treated with a hydraphile at a concentration $1 / 2$ to $1 / 4$ of its MIC and the MIC of the antibiotic determined for the combination. Enhancements in potency up to 30 -fold were observed with certain combinations of bacteria, hydraphiles and antibiotics. ${ }^{66}$

Tryptophan-based amphiphiles that reverse antibiotic resistance

Based on the numerous successful studies involving both indoles or tryptophans and amphiphiles, we prepared a family of bis(tryptophan)s (BTs). ${ }^{67}$ Two groups of structures were prepared. In the first family, tryptophans were linked to $1,2-, 1,3-$, or 1,4-diaminobenzene, affording different geometries and spacings of the tryptophans. In addition, the stereochemistry was varied to assess whether the presence of d-Trp in either relative position would alter the biological activity. In the second family, two tryptophans were linked to the $\alpha, \omega$-positions of linear diamines; these were clearly more flexible compounds that span a greater range of distances than the diaminobenzene derivatives. The compounds prepared are illustrated in Scheme 6.

As described above, the goal was to determine if there was any enhancement in antibiotic potency in the presence of sub-MIC concentrations of any of these BTs. This study involved three different bacteria, two of which were obtained from the ATCC: E. coli K12 and Staphylococcus aureus. The third was a strain of competent $E$. coli that was transformed in our lab with a plasmid containing the tetA efflux pump gene. We refer to this tetracycline-resistant strain as Tet ${ }^{\mathrm{R}}$. The MIC of tetracycline against $\mathrm{Tet}^{\mathrm{R}}$ was $c a .900 \mu \mathrm{M}$. The MIC of minocycline, which is a close structural relative of tetracycline, against Tet $^{\mathrm{R}}$ was $18 \mu \mathrm{M}$.

The MICs were determined for diaminobenzene BTs having side arms in the ortho-, meta- or para-positions against E. coli K12, E. coli $\mathrm{Tet}^{\mathrm{R}}$, and $S$. aureus. The MICs for the ortho- and meta-isomers ranged from $32 \mu \mathrm{M}$ to $64 \mu \mathrm{M}$ for all three bacteria. The para-isomer was less toxic than either of the others, but the MICs were $\geq 128$ $\mu \mathrm{M}$ against all three bacteria. Similarly high MICs were observed for the alkyl BTs when $n=3$, 4, or 6 . In contrast, the MICs for Trp$\left(\mathrm{CH}_{2}\right)_{12}$-Trp against the three bacteria ranged from $4 \mu \mathrm{M}$ to $10 \mu \mathrm{M}$.

We conducted the co-administration experiments described above using the BTs and $\mathrm{Tet}^{\mathrm{R}} E$. coli. In the absence of any adjuvant, the MIC for $\mathrm{Tet}^{\mathrm{R}}$ E. coli was $900 \mu \mathrm{M}$ (as noted above). The BT compounds were added to the growing bacteria at concentrations of either $1 / 2$ or $1 / 4$ MIC and the MIC of tetracycline against the bacterium was determined. To the extent that any enhancement in antibacterial potency was observed, it is expressed as fold-recovery of resistance. Table 2 presents a few of the data obtained in an extensive set of experiments. 


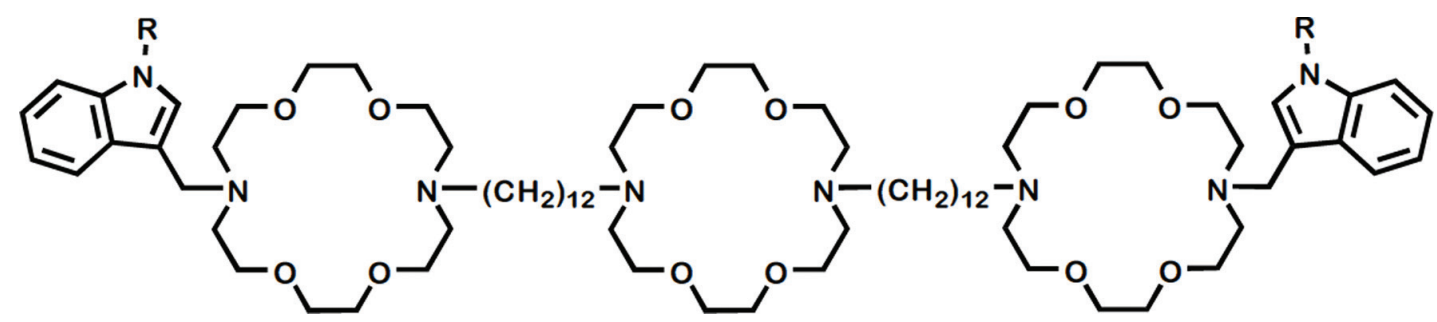

Scheme 4. Structures of 3-indolylmethyl hydraphiles. $\mathrm{R}$ may be $\mathrm{H}$ or $\mathrm{CH}_{3}$.

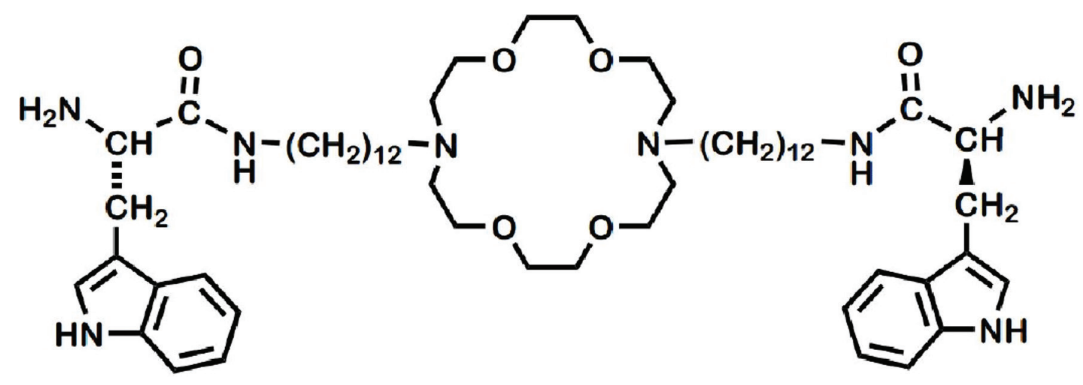

Scheme 5. A hydraphile-inspired amphiphile having tryptophan termini.

The data shown in Table 2 were all obtained against $\operatorname{Tet}^{\mathrm{R}}$ E. coli. Thus, any enhancement in tetracycline potency against this strain is not only an enhancement of efficacy, it is a reversal of resistance. The meta-phenylene compound was studied at both $1 / 2$ and $1 / 4$ MIC (i.e. $24 \mu \mathrm{M}$ or $12 \mu \mathrm{M}$ BT was used in the experiment). Resistance reversal for this compound was 8-fold to 16-fold, depending on the adjuvant concentration. Similarly promising results were obtained for the $\mathrm{BT}$ in which the linker is propylene. A surprising result was that the BT having a $\mathrm{C}_{12}$ connector, representing the most toxic to Tet $^{\mathrm{R}}$ E. coli on its own, showed marginal activity as an adjuvant. At $1 / 2$ MIC, a 4 -fold resistance reversal was observed, so the 2 -fold value is likely a real one.

One of the important questions regarding these potential adjuvants was if, and to what extent, they are toxic to mammalian<smiles>NC(Sc1c[nH]c2ccccc12)C(=O)Nc1cccc(NC(=O)CSc2c[nH]c3ccccc23)c1</smiles><smiles>CNC(=O)[C@H](N)Cc1c[nH]c2ccccc12</smiles>

Scheme 6. Two families of bis(tryptophan)s. Top structure: ortho-, metaand para-isomers and both d- and I-tryptophan stereochemistry. Bottom structure: $n=3,4,6$, or 12 . cells. Thus, the three compounds shown in Table 2 were tested for toxicity against human embryonic kidney (i.e. HEK-293) cells and monkey kidney (i.e. Cos-7) cells. The meta-phenylene BT and the BT having a $\mathrm{C}_{3}$ linker showed $100 \%$ survival (within experimental error) with both cell types. Cells administered with the BT having a $\mathrm{C}_{12}$ linker showed $100 \%$ survival for HEK-293 but only about $70 \%$ survival for Cos-7.

It was important to obtain indications about the ability of the BTs to penetrate and be sustained in bacterial cells. This obviously needed to be contrasted with the undesired ability to penetrate mammalian cells. Experiments were conducted to determine the growth and microscopic characteristics of $\mathrm{Tet}^{\mathrm{R}} E$. coli in the absence of outside influences. A corresponding experiment was conducted in which $0.5 \%(\mathrm{v} / \mathrm{v})$ DMSO was added, because this quantity of solvent was sometimes required to solubilize the amphiphilic adjuvants. The fluorescent dye propidium iodide (PI) was used as a reporter for cellular penetration; while it normally does not pass cellular boundary membranes, when it does, it interacts with intracellular DNA to afford a fluorescent signal.

The effects on $\mathrm{Tet}^{\mathrm{R}}$ E. coli mediated by the meta-phenylene $\mathrm{BT}$, the $\mathrm{C}_{12}$-linked BT and the well-known detergent Triton X-100 were analyzed by confocal microscopy in the presence of PI. Internal fluorescein diacetate (FDA) was used as a reporter of cellular vitality, as the dye is hydrolyzed in situ and the diol is highly fluorescent; its green signal is apparent when no cellular damage has been done. The characteristic green fluorescence was observed for $\mathrm{Tet}^{\mathrm{R}} E$. coli alone and in the presence of $0.5 \% \mathrm{DMSO}$ as well as both the meta-phenylene and $\mathrm{C}_{12}$-linked BTs. No green fluorescence was observed when $0.1 \%$ of Triton X-100 was added.

No PI fluorescence was detected in the groups of bacteria alone or bacteria + DMSO controls. An intense red signal was apparent in the Triton X-100 case, which presumably resulted from an interaction between the DNA that is detritus subsequent to cellular rupture. PI penetration of the meta-phenylene and $\mathrm{C}_{12}$-linked BTs was apparent. This, coupled with the significant FDA signal, confirmed successful penetration of the dye mediated by the BTs. A similar study was undertaken with HEK-293 cells, and in that case, the FDA signal was strong and the PI signal was weak for the control 
Table 2. Reversal of $\operatorname{Tet}^{R}, \mathrm{~s}$ tetracycline resistance by co-administration of bis(tryptophans)

\begin{tabular}{llll}
\hline Rdjuvant & Amount used & Observed MIC $(\mu \mathrm{M})$ & Resistance reversal \\
\hline & & 900 & 16-fold \\
8-fold
\end{tabular}

cells. As above, Triton X-100 ruptured the cells. In the case of both the meta-phenylene and $\mathrm{C}_{12}$-linked BTs, PI penetration was obvious and the FDA signal reported good vitality. ${ }^{67}$ Additional and intense study of the BT class of compounds is currently underway in our laboratory.

\section{Conclusions}

In the past, we have reported the success of several projects involving either indole or tryptophan as a key element. The insights gained from these efforts have led us to a new class of BT amphiphiles that enhance antibiotic potency in sensitive bacteria, but also re-sensitize antibiotic-resistant bacteria. A factor in the success of this approach is certainly enhanced membrane penetration, but we cannot rule out other effects of these novel structures.

\section{Acknowledgments}

We thank the PRF, National Institutes of Health and National Science Foundation (most recent: CHE 1307324) for support of the work described herein that was conducted over many years.

\section{Conflict of interest}

The authors have no conflict of interests related to this publication.

\section{Author contributions}

Bis(tryptophan) synthesis and studies (JWM), antimicrobial studies (MBP), collaborating on studies (SN), preparing the draft for manuscript (SN), revising the manuscript critically for important intellectual content (SN), preparing the draft for manuscript (RC), collaborating on studies (MRG), preparing the draft for manuscript
(MRG), drafting the manuscript (GWG).

\section{References}

[1] Creighton TE. Proteins: structures and molecular properties. Second ed.; W. H. Freeman and Co.: New York, 1993:507.

[2] Tanford C. The Hydrophobic Effect: Formation of micelles and biological membranes (2/e). J. Wiley, New York, 1980:233.

[3] Wallace BA. Gramicidin channels and pores. Annual Rev Biophys 1990;19:127-157. doi:10.1146/annurev.bb.19.060190.001015.

[4] Ketchem RR, Hu W, Cross TA. High-resolution conformation of gramicidin $A$ in a lipid bilayer by solid-state NMR. Science 1993;261(5127):1457-1460. doi:10.1126/science.7690158.

[5] Wallace BA. Gramicidin and related ion channel-forming peptides. Novartis Foundation, John Wiley \& Sons, Ltd.: Chichester, 1999; 225:273.

[6] Doyle DA, Morais Cabral J, Pfuetzner RA, Kuo A, Gulbis JM, Cohen $\mathrm{SL}$, et al. The structure of the potassium channel: molecular basis of $\mathrm{K}+$ conduction and selectivity. Science 1998;280(5360):69-77. doi:10.1126/science.280.5360.69.

[7] Kelkar DA, Chattopadhyay A. The gramicidin ion channel: a mode membrane protein. Biochim Biophys Acta 2007;1768(9):2011-2025. doi:10.1016/j.bbamem.2007.05.011.

[8] Burkhart BM, Duax WL. Gramicidin channel controversy - reply. Nat Struct Biol 1999;6(7):611-612. doi:10.1038/10652.

[9] Cross TA, Arseniev A, Cornell BA, Davis JH, Killian JA, Koeppe RE 2nd, et al. Gramicidin channel controversy - revisited. Nat Struct Biol 1999;6(7):610-611. doi:10.1038/10650.

[10] Stankovic CJ, Heinemann SH, Schreiber SL. Immobilizing the gate of a tartaric acid-gramicidin A hybrid channel molecule by rational design. J. Am. Chem. Soc 1990;112:3702-3704. doi:10.1021/ja00165a089.

[11] Pfeifer JR, Reiß P, Koert U. Crown ether-gramicidin hybrid ion channels: dehydration-assisted ion selectivity. Angew Chem Int Ed Engl 2006;45(3):501-504. doi:10.1002/anie.200502570.

[12] Barboiu M, Le Duc Y, Gilles A, Cazade PA, Michau M, Marie Legrand $\mathrm{Y}$, et al. An artificial primitive mimic of the Gramicidin-A channel. Nat Commun 2014;5:4142. doi:10.1038/ncomms5142.

[13] Jentsch TJ, Pusch M, Rehfeldt A, Steinmeyer K. The ClC family of voltage-gated chloride channels: structure and function. Ann N Y Acad Sci 1993;707:285-293. doi:10.1111/j.1749-6632.1993.tb38059.x.

[14] Dutzler R, Campbell EB, Cadene M, Chait BT, MacKinnon R. X-ray 
structure of a clc chloride channel at 3.0 a reveals the molecular basis of anion selectivity. Nature 2002;415(6869):287-294. doi:10.1038/415287a.

[15] Townsley LE, Tucker WA, Sham S, Hinton JF. Structures of gramicidins A, B, and C incorporated into sodium dodecyl sulfate micelles. Biochemistry 2001;40(39):11676-11686. doi:10.1021/bi010942w.

[16] Schiffer $M$, Chang $C H$, Stevens FJ. The functions of tryptophan residues in membrane proteins. Protein Eng 1992;5(3):213-214. doi:10.1093/protein/5.3.213.

[17] Jacobs RE, White $\mathrm{SH}$. The nature of the hydrophobic binding of small peptides at the bilayer interface: implications for the insertion of transbilayer helices, Biochemistry. 1989;28(8):3421-3437. doi:10.1021/bi00434a042.

[18] Schore NE, Turro NJ. Novel fluorescent probe for micellar systems. 1,3-dialkylindoles. J Am Chem Soc 1975;97:2488-2496. doi:10.1021/ ja00842a028.

[19] Israelachvili JN. Intermolecular and Surface Forces. 3rd ed.; Elsevier: Amsterdam, 2011:674.

[20] Kunitake T, Okahata Y, Shimomura M, Yasunami S, Takarabe K. Formation of stable bilayer assemblies in water from single-chain amphiphiles. Relationship between the amphiphile structure and the aggregate morphology. J Am Chem Soc 1981;103(18):5401-5413. doi:10.1021/ja00408a021.

[21] Reutov OA, Beletskaya IP, Kurts AL. Ambident Anions; Consultants Bureau, Plenum Publishing Co., New York, 1983:338.

[22] Abel E, Fedders MF, Gokel GW. Vesicle formation from N-alkylindoles: implications for tryptophan-water interactions. J Am Chem Soc 1995;117(4):1265-1270. doi:10.1021/ja00109a010.

[23] Abel E, De Wall SL, Edwards WB, Lalitha S, Covey DF, Gokel GW. Aggregate formation from 3-alkylindoles: amphiphilic models for interfacial helix anchoring groups. Chem Commun 2000;(6):433-434. doi:10.1039/A909527F.

[24] Abel E, De Wall SL, Edwards WB, Lalitha S, Covey DF, Gokel GW. Formation of stable vesicles from $\mathrm{N}$ - or 3-alkylindoles: possible evidence for tryptophan as a membrane anchor in proteins. J Org Chem 2000;65:5901-5909. doi:10.1021/jo000040l.

[25] Szoka F Jr, Papahadjopoulos D. Procedure for preparation of liposomes with large internal aqueous space and high capture by reverse-phase evaporation, Proc Natl Acad Sci U S A. 1978;75(9):41944198.

[26] Saunders L, Perrin J, Gammack D. Ultrasonic irradiation of some phospholipid sols. J Pharm Pharmacol 1962;14:567-572. doi:10.1111/j.2042-7158.1962.tb11141.x.

[27] Gokel GW. Hydraphiles: Design, Synthesis, and Analysis of a Family of Synthetic, Cation-Conducting Channels. Chem Commun 2000;(1):19. doi:10.1039/A903825F.

[28] Murillo O, Watanabe S, Nakano A, Gokel GW. Synthetic models for transmembrane channels: structural variations that alter cation flux. J Am Chem Soc 1995;117:7665-7679. doi:10.1021/ja00134a011.

[29] Abel E, Maguire GEM, Meadows ES, Murillo O, Jin T, Gokel GW. Planar bilayer conductance and fluorescent studies confirm the function and location of a synthetic sodium-ion-conducting channel in a phospholipid bilayer membrane. J Am Chem Soc 1997;119(38):90619062. doi:10.1021/ja971098t.

[30] Leevy WM, Huettner JE, Pajewski R, Schlesinger PH, Gokel GW. Synthetic ion channel activity documented by electrophysiological methods in living cells. J Am Chem Soc 2004;126(48):15747-15753. doi:10.1021/ja046626x.

[31] Leevy WM, Donato GM, Ferdani R, Goldman WE, Schlesinger PH, Gokel GW. Synthetic hydraphile channels of appropriate length kill Escherichia coli. J Am Chem Soc 2002;124(31):9022-9023. doi:10.1021/ja017052o.

[32] Weber ME, Schlesinger PH, Gokel GW. Dynamic assessment of bilayer thickness by varying phospholipid and hydraphile synthetic channel chain lengths. J Am Chem Soc 2005;127(2):636-642. doi:10.1021/ ja044936+.

[33] Leevy WM, Weber ME, Schlesinger PH, Gokel GW. NMR and ion selective electrode studies of hydraphile channels correlate with biological activity in E. coli and B. subtilis. Chem Commun 2005;7(1):8991. doi:10.1039/b413588a.

[34] Murray CL, Gokel GW. Cation flux dependence on carbon chain length in tris(macrocycle) channels as assessed by dynamic 23Na NMR studies in phospholipid bilayers. Chem Commun 1998;(22):2477-2478. doi:10.1039/A806317F

[35] Srinivas G, Lopez C, Klein M. Membrane bound hydraphiles facilitate cation translocation. J Phys Chem B 2004;108(14):4231-4235. doi:10.1021/jp036953b.

[36] Skelton AA, Khedkar VM, Fried JR. All-atom molecular dynamics simulations of an artificial sodium channel in a lipid bilayer: the effect of water solvation/desolvation of the sodium ion. J Biomol Struct Dyn 2016;34(3):529-539. doi:10.1080/07391102.2015.1044473.

[37] Skelton AA, Agrawala N, Fried JR. Quantum mechanical calculations of the interactions between diazacrowns and the sodium cation: an insight into $\mathrm{Na}+$ complexation in diazacrown-based synthetic ion channels. RSC Adv 2015;5:55033-55047. doi:10.1039/C4RA14000A

[38] Abel E, Maguire GEM, Murillo O, Suzuki I, DeWall SL, Gokel GW. Hydraphile channels: structural and fluorescent probes of position and function in a phospholipid bilayer. J Am Chem Soc 1999;21(39):90439052. doi:10.1021/ja9909172.

[39] Hinman RL, Lang J. The Protonation of indoles. basicity studies. the dependence of acidity functions on indicator structure. J Am Chem Soc 1964;86:3796-3806. doi:10.1021/ja01072a040.

[40] Nakano A, Xie Q, Mallen JV, Echegoyen L, Gokel GW. Synthesis of a membrane-insertable, sodium cation conducting channel: kinetic analysis by dynamic sodium-23 NMR. J Am Chem Soc 1990;112(3):1287-1289. doi:10.1021/ja00159a083.

[41] Abel E, Gokel GW. unpublished results.

[42] Sunner J, Nishizawa K, Kebarle P. Ion-solvent interactions in the gas phase. The potassium ion and benzene. J Phys Chem 1981;85(13):1814-1820. doi:10.1021/j150613a011.

[43] Guo BC, Purnell JW, Castleman AW Jr. The clustering reactions of benzene with sodium and lead ions. Chem Phys Lett 1990;168(2):155160. doi:10.1016/0009-2614(90)85122-S.

[44] Meot-Ner M, Deakyne CA. Unconventional ionic hydrogen bonds. 1. CHdelta $+\bullet \bullet X$. Complexes of quaternary ions with - and pi-donors. J Am Chem Soc 1985;107(2):469-474. doi:10.1021/ja00288a033.

[45] Kumpf RA, Dougherty DA. A mechanism for ion selectivity in potassium channels: computational studies of cation-pi interactions. Science 1993;261(5129):1708-1710. doi:10.1126/science.8378771.

[46] Heginbotham L, Lu Z, Abramson T, MacKinnon R. Mutations in the $\mathrm{K}+$ channel signature sequence. Biophys J 1994;66(4):1061-1067. doi:10.1016/S0006-3495(94)80887-2.

[47] Gokel GW, Echegoyen L. Dugas H. Lariat ethers in membranes and as membranes. Bioorganic Chemistry Frontiers 1990;1:BerlinSpringer Verlag115-141.

[48] Arnold KA, Viscariello AM, Kim M, Gandour RD, Fronczek FR, Gokel GW. N,N'-bis(Substituted)-4,13-diaza-18-crown-6 derivatives having pi-donor-group-sidearms: correlation of thermodynamics and solid state structures. Tetrahedron Lett 1988;29(25):3025-3028. doi:10.1016/0040-4039(88)85076-7.

[49] De Wall SL, Barbour LJ, Gokel GW. Cation-pi complexation of potassium cation with the phenolic sidechain of tyrosine. J Am Chem Soc 1999;121(36):8405-8406. doi:10.1021/ja991618f.

[50] De Wall SL, Meadows ES, Barbour LJ, Gokel GW. Synthetic receptors as models for alkali metal cation-pi binding sites in proteins. Proc Natl Acad Sci U S A 2000;97(12):6271-6276. doi:10.1073/ pnas.97.12.6271.

[51] Gokel GW, Barbour LJ, Ferdani R, Hu J. Lariat ether receptor systems show experimental evidence for alkali metal cation-pi interactions. Acc Chem Res 2002;35(10):878-886. doi:10.1021/ar000093p.

[52] Petersen FN, Jensen $M \varnothing$, Nielsen $C H$. Interfacial tryptophan residues: a role for the cation-pi effect?. Biophys J 2005;89(6):3985-96 doi:10.1529/biophysj.105.061804.

[53] Hu J, Barbour LJ, Gokel GW. The indole sidechain of tryptophan as a versatile pi-donor. J Am Chem Soc 2002;124(37):10940-10941. doi:10.1021/ja020586k.

[54] Hu J, Barbour LJ, Gokel GW. Probing alkali metal-pi interactions with the side chain residue of tryptophan. Proc Natl Acad Sci U S A 2002;99(8):5121-5126. doi:10.1073/pnas.082645599.

[55] Schlesinger PH, Ferdani R, Liu J, Pajewska J, Pajewski R, Saito M, et al. SCMTR: a chloride-selective, membrane-anchored peptide channel that exhibits voltage gating. J Am Chem Soc 2002;124(9):1848-1849. 
doi:10.1021/ja016784d.

[56] Dutzler R, Campbell EB, MacKinnon R. Gating the Selectivity Filter in ClC Chloride Channels. Science 2003;300(5616):108-112. doi:10.1126/science. 1082708

[57] Gokel GW, Barkey N. Transport of Chloride Ion through Phospholipid Bilayers Mediated by Synthetic Ionophores. New J Chem 2009;33:947-963. doi:10.1039/B817245P.

[58] Schlesinger PH, Djedovic NK, Ferdani R, Pajewska J, Pajewski R, Gokel GW. Anchor chain length alters the apparent mechanism of chloride channel function in SCMTR derivatives. Chem Commun (Camb) 2003;308-309. doi:10.1039/B211629B.

[59] Pajewski R, Pajewska J, Li R, Daschbach MM, Fowler EA, Gokel GW. The effect of midpolar regime mimics on anion transport mediated by amphiphilic heptapeptides. New J Chem 2007;31:1960-1972. doi:10.1039/B705179B.

[60] Elliott EK, Stine KJ, Gokel GW. Air-water interfacial behavior of amphiphilic peptide analogs of synthetic chloride ion transporters. J Membr Sci 2008;321(1):43-50. doi:10.1016/j.memsci.2008.01.048.

[61] Cook GA, Pajewski R, Aburi M, Smith PE, Prakash O, Tomich JM, et al. NMR structure and dynamic studies of an anion-binding, channel-forming heptapeptide. J Am Chem Soc 2006;128(5):1633-1638. doi:10.1021/ja055887j.
[62] Daschbach MM, Negin S, You L, Walsh M, Gokel GW. Aggregation and supramolecular membrane interactions that influence anion transport in tryptophan-containing synthetic peptides. Chemistry 2012;18(24):7608-7623. doi:10.1002/chem.201103203.

[63] Ferdani R, Gokel GW. Planar bilayer studies reveal multiple conductance states for synthetic anion transporters. Org Biomol Chem 2006;4(20):3746-50. doi:10.1039/b609345k.

[64] Atkins JL, Patel MB, Cusumano Z, Gokel GW. Enhancement of antimicrobial activity by synthetic ion channel synergy. Chem Commun (Camb) 2010;46(43):8166-8167. doi:10.1039/c0cc03138k.

[65] MIC, Clinical and Laboratory Standards Institute: M07-A9, Methods for dilution antimicrobial susceptibility tests for bacteria that grow aerobically; Approved standard, ISBN 1-56238-784-7, www.clsi.org 2012, Ninth Edition.

[66] Patel MB, Garrad EC, Stavri A, Gokel MR, Negin S, Meisel JW. Hydraphiles enhance antimicrobial potency against escherichia coli, pseudomonas aeruginosa, and bacillus subtilis. Bioorg Med Chem 2016;24(12):2864-2870. doi:10.1016/j.bmc.2016.04.058.

[67] Meisel JW, Patel MB, Garrad E, Stanton RA, Gokel GW. Novel reversal of tetracycline resistance in escherichia coli by noncytotoxic bis(tryptophan)s. J Am Chem Soc 2016;138(33):10571-10577. doi:10.1021/jacs.6b05578. 